\title{
GENOTYPE $\times$ ENVIRONMENT INTERACTION AND IDENTIFICATION OF HIGH YIELDING WHEAT GENOTYPES FOR AFGHANISTAN
}

\author{
Darya Khan Akbarzai ${ }^{1}$, Yashpal Saharawat ${ }^{1, *}$, Lina Mohammadi ${ }^{1}$, Abdul Rahman Manan ${ }^{1}$, \\ Assadullah Habibi ${ }^{1}$, Srinivas Tavva ${ }^{1}$, Swain Nigamananda ${ }^{1}$ and Murari $\operatorname{Singh}^{2}$ \\ ${ }^{1}$ International Center for Agricultural Research in the Dry Areas (ICARDA), Kabul, Afghanistan \\ ${ }^{2}$ International Center for Agricultural Research in the Dry Areas (ICARDA), Amman, Jordan
}

Received - March 24, 2017; Revision - April 17, 2017; Accepted - May 06, 2017

Available Online - May 12, 2017

DOI: http://dx.doi.org/10.18006/2017.5(2).225.234

\section{KEYWORDS}

Spring Bread Wheat

Genotypes $\times$ environment

interaction

Stability

GGE biplot

Specific adaptation

Afghanistan

\begin{abstract}
Wheat is a key cereal for human consumption in Afghanistan but has low productivity stemmed from various biotic and abiotic stresses and soil factors. To quantify the limitations to yield productivity, two sets of wheat genotypes from earlier selections were evaluated in three sets of trials in incomplete block designs at locations in three provinces (Baghlan, Mazar and Nangarhar) of Afghanistan during 2014-15 and 2015-16 growing seasons. Genotype (G) effects, its interactions with location (GLI) and with year within locations (GYI) were evaluated with a view to identify high yielding and specifically adapted genotypes. In each trial at each location genotypic differences were significant $(\mathrm{P}<0.05)$ except at one location in an irrigated trial. GLI and GYI were also significant. Genotype + Genotype $\times$ Environment (GGE) interaction biplot was used to identify the genotypes specifically adapted to a location in Afghanistan. The high yielding spring bread wheat genotypes that were identified included: HAMAMA4 for all the locations and genotype SG10 (SER.1B*2/3/KAUZ*2/BOW//KAUZ/4/KAUZ/FLORKWA1) for Baghlan and Nangarhar under moderate to high rainfall; and IG8 (VEE\#7//MT773/EMUS/3/SAFI-1) for all the locations and IG4 (BT1735/ACHTAR//FSFOOR-1) for Baghlan under irrigated or a higher rainfall. The third trial comprised elite spring bread wheat evaluated under irrigated conditions, where Solh 2002 variety was found to be high yielding and broadly adapted to these locations. These genotypes can be used for large-scale production to support food security in Afghanistan.
\end{abstract}

* Corresponding author

E-mail: y.saharawat@cgiar.org (Yashpal Singh Saharawat)

Peer review under responsibility of Journal of Experimental Biology and Agricultural Sciences.

Production and Hosting by Horizon Publisher India [HPI] (http://www.horizonpublisherindia.in/).

All rights reserved.
All the article published by Journal of Experimental Biology and Agricultural Sciences is licensed under a Creative Commons Attribution-NonCommercial 4.0 International License Based on a work at www.jebas.org.

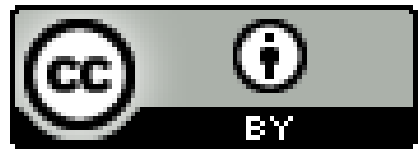




\section{Introduction}

Wheat (Triticum aestivum L.) is one of the most important cereal crop grown in Afghanistan. Cultivated under both irrigated and dry land cropping systems, wheat is produced on an area of 2.4 million ha annually in Afghanistan (CSO, 2014). Before the war in Afghanistan in 1979 , cereals were grown on about $87 \%$ of all cultivated land with wheat planted on $57 \%$ of the cultivated land. The range of elevations for wheat cultivation is from 300 to 3500 meters above sea level. The majority of wheat grown in Afghanistan is fall (winter)-sown. The facultative type of wheat occupies $80 \%$ or more of the area, while winter types cover $20 \%$ of the total wheat area. Per capita consumption of wheat is estimated at 170kg/person/year (RASTA, 2012). In 1976-77, Afghanistan became self-sufficient in wheat, and average yield increased from $832 \mathrm{~kg} / \mathrm{ha}$ to $1131 \mathrm{~kg} / \mathrm{ha}$ in 1978 , but self-sufficiency was not sustained. The potential for yield increases is high with the use of improved varieties and improved agro-techniques. With the introduction of improved wheat varieties and the use of proper inputs, average yield increased to $2,500 \mathrm{~kg} / \mathrm{ha}$ on farmer's fields (Manan \& Wassimi, 2003). Nearly a quarter of Afghanistan's domestic requirements for wheat are met through imports. On an average, over the past five years, Afghanistan produced 4.7 million MT and imported about 1.7 million MT annually. Over this period, Afghanistan's wheat imports have been split evenly between Kazakhstan and Pakistan though annually the proportions of imports vary (FEWS Net, 2015). Agricultural production in Afghanistan is highly dependent on rain and snowfall. Approximately $45 \%$ of Afghanistan's wheat area in a normal year is irrigated, while the remaining $55 \%$ depends entirely on rainfall. The timing and quantity of the annual snowmelt is a key factor in determining the quantity and duration of water availability for irrigation throughout the cultivated areas of Afghanistan. Productivity of wheat differs significantly between irrigated and rainfed areas. Average wheat yield (without fertilizers) on irrigated land is about $2.7 \mathrm{MT} / \mathrm{ha}$ (3.5 MT/ha with fertilizer) versus only 1.1 MT/ha on rain-fed land (World Bank, 2008).

Afghanistan has low productivity $(2.23 \mathrm{t} / \mathrm{ha})$ in contrast to its neighbors, India (3.03 t/ha), Tajikistan (2.97t/ha) and Pakistan $(2.82 \mathrm{t} / \mathrm{ha})(\mathrm{FAO}, 2014)$ and there is a need to increase the yield and production to fill the current gap and to achieve selfsufficiency in wheat production. To meet the staple food requirement of an increasing Afghanistan population, it is necessary to develop wheat cultivars, which are high yielding and stable over the locations. To achieve this goal requires multienvironment evaluation of prospective wheat genotypes and quantifying genotype $\times$ environment interactions (GEI). A wide literature on techniques and tools are available for examination and exploitation of GEI (Finlay \& Wilkinson, 1963; Eberhart \&Russell, 1966; Basford \& Cooper, 1998; Lin \& Binns 1988; Gauch \& Zobel, 1988; Delacy et al.,1996a; Delacy et al.,1996b; Sharma et al., 2010). In presence of GEI, genotype plus genotype $\times$ environment (GGE) interaction biplot analysis is an appropriate tool to represent the environments and specific adaptation of a genotype to an environment (Yan et al., 2000) and has been applied in numerous studies on wheat (Jambormias \& Riry, 2008; Asfaw et al., 2009; Jambormias, 2011). GGE biplot analysis provides an easy and comprehensive solution to genotype by environment data analysis, where GEI has been a challenge to plant breeders, geneticists, and agronomists (Yan \& Tinker, 2006).

A collection of spring sowing bread wheat genotypes were made available from earlier selections and evaluations carried out at the International Center for Agricultural Research for the Dry Areas (ICARDA), Aleppo, Syria. With a view that some of these specific genotype may be suitable for improving the wheat based food security in Afghanistan, the following objectives for this study were set: a) to evaluate the genotypic differences among the set of specific wheat cultivars from three type of trials, b) to examine the presence of genotype and environment interaction (GEI) and partition the interaction into spatial (location) and temporal (year) components, and c) to identify the high yielding genotypes with wide adaptation or specific adaptation.

\section{Materials and Methods}

\subsection{Genetic Material and Environments}

In Afghanistan, ICARDA has been evaluating different genetic material (lines/varieties) suitable for fall and spring seasons sowing for high yielding, resistant to disease (rust, Fusarium wilt and Ascochyta blight), and wide adaptability to locations. The genetic materials for spring season - sowing were evaluated in three trials denoted by: 1) 14th-SBWYT 2014-15 or, simply SBWYT standing for a spring-sown bread wheat yield trial for low rainfall (250-400 $\mathrm{mm}$ ) areas, 2) 14th-ISBWYT2014-15, or ISBWYT for irrigated spring-sown bread wheat yield trial. Irrigation was not applied if a moderate to high rainfall (>400 mm) occurred, and 3) 14thESBWYT2014-15, or ESBWYT for an elite spring-sown bread wheat yield trial for low rainfall areas. In each of the trials, up to three surface irrigations during cropping season were applied to ensure the expected moisture levels of the respective areas. The genotypes under the trials SBWYT, ISBWYT and ESBWYT are denoted by the sequences SG1 to SG15, IG1 to IG10 and EG1 to EG10 and are given in Table 1. These trials were conducted during 2014-15 and 2015-16 at three locations: Mazar ( $36^{\circ} 3925.4$ $\mathrm{N}, 66^{\circ} 5739.9 \mathrm{E}, 398 \mathrm{~m}$ asl), Baghlan $\left(36^{\circ} 052903 \mathrm{~N}, 68^{\circ} 3849\right.$ $44 \mathrm{E}, 599 \mathrm{~m}$ asl) and Nangarhar ( $34^{\circ} 25 \mathrm{~N}, 70^{\circ} 27 \mathrm{E}, 552 \mathrm{~m}$ asl) in Afghanistan. The soil type in these provinces is broadly clay loam. The annual precipitation during 2015 was $191 \mathrm{~mm}$ at Baghlan (driest of the three locations), $226 \mathrm{~mm}$ at Nangarhar and $282 \mathrm{~mm}$ at Mazar (the wettest) location. The average daily temperature was $15.81^{\circ} \mathrm{C}$ at Baghlan (coolest of the three locations), $18.95{ }^{\circ} \mathrm{C}$ at Mazar and $23.07{ }^{\circ} \mathrm{C}$ at Nangarhar (hottest of the locations).

\subsection{Experimental Design}

The trials were conducted in incomplete block designs (alpha designs) which has a relatively better control on field variation compared to complete blocks. 
Table 1 List of wheat genotypes used in the three trials.

\section{Spring bread wheat yield trials (SBWYT)}

\section{Genotype Genotype name}

code

SG1 ATTILA 50Y//ATTILA/BCN/3/PFAU/MILAN

SG2 ATTILA//VORONA/TR810200 IG2

SG3 HADIAH-14/3/MUNIA/CHTO//MILAN

SG4 HAMAMA-4 IG4

SG5 ICARDA-SRR-9/JAWAHIR-22 IG5

\begin{tabular}{lll}
\hline SG6 & ICARDA-SRR-9/JAWAHIR-23 & IG6 \\
SG7 & J15418/MARAS//NOVOSADSKA & IG7
\end{tabular}

\begin{tabular}{|lll}
\hline SG8 & OPATA/RAYON//KAUZ/3/PFAU/MILAN & IG8 \\
\hline SG9 & PVW343*2/KUKUN//22SAWSN-97 & IG9 \\
\hline SG10 & SER $1 \mathrm{~B} * 2 / 3 /$ KAUZ*2/BOW//KAUZ/4/KAUZ/FLORKWA-1
\end{tabular}

\begin{tabular}{ll} 
SG10 & SER.1B*2/3/KAUZ*2/BOW//KAUZ/4/KAUZ/FLORKWA-1 \\
\hline SG11 & SER.1B*2/3/KAUZ*2/BOW//KAUZ/4/KAUZ/FLORKWA-2
\end{tabular}

SG12 SER.1B*2/3/KAUZ*2/BOW//KAUZ/4/PFAU/MILAN

SG13 SOMAMA-9/ICARDA-SRRL-2

SG14 WEAVER/WL3928//SW 89.3046/3/HADIAH-14

SG15 Lalmi-2 (Check)

Elite spring bread wheat yield trials (ESBWYT)

Genotype Genotype name

code

EG1 ATTLLA//VORONA/TR810200

\begin{tabular}{ll}
\hline EG2 & VMP/MOS \\
\hline EG3 & DAGDAS/APCB-40 \\
\hline
\end{tabular}

EG4 ZANDER-6/6/MNCH/5/BLL/F72.23/4/TILLA//2*FR/K

EG5 ZANDER-17/SIDS-5

EG6 Solh 2002 (check)

EG7 LAKTA-1/QAFZAH-21

EG8 YAMAMA/SD 8036

EG9 JAWAHIR-13

EG10 National check ( Lalmi-2)

In trial SBWYT, 15 genotypes were evaluated in blocks of size 5 and 4 replications at each of Baghlan, Mazar and Nangarhar. Trials, ISBWYT and ESBWYT, had 10 genotypes with block size 5 and 4 replications at each of Baghlan, Mazar and Nangarhar. In all the trials, the genotypes were planted in $4.5 \mathrm{~m}^{2}$ plots of 6 rows, each $2.5 \mathrm{~m}$ long, with a row-to-row distance of $30 \mathrm{~cm}$. The yield collected from the central area of $1.8 \mathrm{~m}^{2}$ was converted to ton per hectare ( $\mathrm{t} / \mathrm{ha}$ ) for analysis.

\subsection{Statistical methods}

Data from individual locations were analyzed by fitting a linear model in replicate effects, incomplete block effects within replicates and genotype effects. Since our interest was in evaluating and comparing these specific genotypes, their effects were assumed as fixed while the effects of replicates and blocks within replicates were assumed random, and the model for yield

Irrigated spring bread wheat yield trials (ISBWYT)

\section{Genotype Genotype name}

code

IG1 HUBARA-5/3SHA3/SERI/SHA4/LIRA

IG2 HUBARA-3*2/SHUHA-4

IG3 MEXIPAK65/ASFOOR-1

IG4 BT1735/ACHTAR//FSFOOR-1

IG5 SHUHA-8/DUCULA

IG6 ZAIN-4

IG7 ATTENA-1GAMDOW-3/3/MON"S"/ALD, S,//ALDAN

IG8 VEE\#7//MT773/EMUS/3/SAFI-1

G9 MOUKA-4/RAYON

G10 National check (Kohdasht)


Table 2 Trial description, grain yield means, coefficient of variation (CV), efficiency of incomplete blocks and significance of genotypic effects.

\begin{tabular}{|c|c|c|c|c|c|c|c|}
\hline Trial name $^{\dagger}$ & Year & Location name & No. of genotypes & Mean (t/ha) & $\mathrm{CV}(\%)$ & Efficiency (\%) & P-value (genotypes) \\
\hline \multirow[t]{6}{*}{ SBWYT } & 2014-15 & Baghlan & 15 & 4.85 & 10.0 & 105 & $<0.001$ \\
\hline & & Mazar & 15 & 4.67 & 8.9 & 100 & 0.003 \\
\hline & & Nangarhar & 15 & 4.03 & 8.5 & 100 & $<0.001$ \\
\hline & $2015-16$ & Baghlan & 15 & 4.22 & 8.6 & 112 & $<0.001$ \\
\hline & & Mazar & 15 & 2.59 & 11.7 & 170 & 0.003 \\
\hline & & Nangarhar & 15 & 4.02 & 13.4 & 100 & $<0.001$ \\
\hline \multirow[t]{6}{*}{ ISBWYT } & 2014-15 & Baghlan & 10 & 8.50 & 11.6 & 100 & $<0.001$ \\
\hline & & Mazar & 10 & 4.63 & 12.4 & 102 & 0.074 \\
\hline & & Nangarhar & 10 & 4.90 & 8.5 & 100 & 0.011 \\
\hline & 2015-16 & Baghlan & 10 & 2.65 & 10.7 & 102 & 0.000 \\
\hline & & Mazar & 10 & 2.53 & 17.4 & 100 & 0.005 \\
\hline & & Nangarhar & 10 & 4.43 & 18.4 & 119 & 0.024 \\
\hline \multirow[t]{6}{*}{ ESBWYT } & 2014-15 & Baghlan & 10 & 6.89 & 9.1 & 100 & $<0.001$ \\
\hline & & Mazar & 10 & 4.94 & 7.2 & 100 & $<0.001$ \\
\hline & & Nangarhar & 10 & 3.88 & 5.1 & 100 & $<0.001$ \\
\hline & $2015-16$ & Baghlan & 10 & 3.88 & 8.1 & 142 & $<0.001$ \\
\hline & & Mazar & 10 & 2.15 & 14.4 & 131 & 0.002 \\
\hline & & Nangarhar & 10 & 3.87 & 10.3 & 108 & $<0.001$ \\
\hline
\end{tabular}

Each of these trials was implemented in an alpha design; with blocks of size 5 and 4 replications. $C V=C o e f f i c i e n t$ of variation; $P$-value $=$ Probability of observing the extreme data in the absence of genotypes effects

Data combined over locations for a given year:

VCOMPONENTS [Fixed=Geno+ Loc + Geno. Loc] Loc.Rep + Loc.Rep.Blk ; constraints=positive

Data combined over locations and years:

VCOMPONENTS [Fixed=Geno+ Loc + Geno. Loc] Year.Loc + Geno.Year.Loc+ Year.Loc.Rep $\quad+$ Year.Loc.Rep.Blk ; constraints=positive

where Yield, Rep, Blk, Geno, Loc and Year represent vectors containing plot-wise values for the yield (response), replicates, blocks within replicates, genotypes, locations and years, respectively. For specific adaptation of genotypes to location was carried out using its GGE biplot (Yan et al., 2000; Yan 2011). Calculations were also carried out in GenStat software environment (VSN Inc., 2015)

\section{Results and Discussion}

3.1 Genotypic differences at individual locations within trials

Table 2 presents the summary statistic of the trial means over all the genotypes, coefficient of variation (CV), efficiency of incomplete blocks, and P-value to show the significance of genotypic differences in mean yields. In SBWYT evaluated at three locations, genotypic variation was highly significant at all the locations ( $\mathrm{P}$ in the range $<0.001-0.003$ ) and location-year mean overall the genotypes varied from $2.59 \mathrm{t} / \mathrm{ha}$ to $4.85 \mathrm{t} / \mathrm{ha}$, the $\mathrm{CV}$ for the experimental error from 8.5 to $13.4 \%$. The incomplete blocks were effective in three of the six datasets with efficiency in the range 105-170\% compared to complete blocks. In ISBWYTs, the mean grain yield varied from $2.53 \mathrm{t} / \mathrm{ha}$ to $8.50 \mathrm{t} / \mathrm{ha}$, efficiency of incomplete blocks varied in the range $102-119 \%$ in three out of six datasets and $\mathrm{CV}$ for the experimental error ranged from 8.5 $18.4 \%$. Genotypic differences were significant at all the locations and years ( $\mathrm{P}<0.001-0.024)$, except at Mazar in 2014-15. In ESBWYT, incomplete blocks were effective in three cases, the mean varied from $2.15 \mathrm{t} / \mathrm{ha}$ to $6.89 \mathrm{t} / \mathrm{ha}$, and $\mathrm{CV}$ for the experimental error varied from 5.1 to $14.4 \%$. Genotypic variation was highly significant in each of the six datasets. The low CV value indicated that the models were successful in capturing the field heterogeneity and low P-values showed the powerful differentiation between the genotypes (Table 2).

\subsection{Genotypex Environment Interaction}

Year-wise data analysis showed that genotype $\times$ location interactions (GLI) were significant $(\mathrm{P}<0.001)$ in all the trials (Table $3 \mathrm{~A})$. In the presence of such interactions, the genotypic variation (G) averaged over locations was also significant $(\mathrm{P}<0.001)$. When datasets were combined over locations and years, genotype $\times$ year interaction $(\mathrm{GYI})$ within locations was significant $(\mathrm{P}<0.05)$ for each trial (Table 3B). In the presence of GYI, GLI and G were significant $(\mathrm{P}<0.05)$, except for SBWYT where GLI was not significant $(\mathrm{P}=0.184)$. 
Table 3 Significance of genotype, genotype $\times$ environment interaction and variance components in wheat in Afghanistan

Table 3A: Year-wise significance of $G$ and $G \times L$ interaction and error variance

\begin{tabular}{|lcccccc|}
\hline Sources of interest & \multicolumn{2}{c}{ SBWYT } & \multicolumn{2}{c}{ ISBWYT } & ESBWYT \\
\hline & $2014-15$ & $2015-16$ & $2014-15$ & $2015-16$ & $2014-15$ & $2015-16$ \\
\hline \multicolumn{7}{c}{} \\
\hline
\end{tabular}

Table 3B: Significance of G, GLI and GYI within L and Variance components

\begin{tabular}{|c|c|c|c|}
\hline Sources of interest & SBWYT & ISBWYT & ESBWYT \\
\hline & \multicolumn{3}{|c|}{$\mathrm{P}$-value } \\
\hline Genotype (G) & $<0.001$ & 0.034 & $<0.001$ \\
\hline $\mathrm{G} \times \mathrm{L}$ Interaction(GLI) & 0.184 & 0.023 & 0.022 \\
\hline \multirow[t]{2}{*}{ G $\times$ Year $(Y)$ interaction $(G Y I)$ within $L$} & 0.004 & 0.040 & 0.003 \\
\hline & \multicolumn{3}{|c|}{ Estimated variance } \\
\hline GYI within $\mathrm{L}$ & $0.0693 \pm 0.0257$ & $0.1022 \pm 0.0583$ & $0.1223 \pm 0.0449$ \\
\hline Error & $0.1730 \pm 0.0169$ & $0.415 \pm 0.0495$ & $0.156 \pm 0.019$ \\
\hline
\end{tabular}

This indicates that the differential response patterns of genotype with locations vary with years. Biologically, this may occur when the contribution (or level of expression) of the genes regulating a specific trait differs among environments (Basford \& Cooper, 1998). Therefore, we examined adaptation of the genotypes to the locations using GGE biplot for individual years.

\subsection{Identification of specifically adapted genotypes}

GGE biplots are graphical representation of the genotype plus genotype $\times$ environment interaction, i.e., G + GLI in case of locations, matrix in a two-dimensional layout with points representing the genotypes and locations, a polygon is drawn connecting the vertices as the genotypes with extreme values of GGE and perpendiculars from the center are drawn on the sides of the polygon. Furthermore, the set of environments contained in a sector or region formed by the perpendiculars on the neighboring sides of the polygon connecting the vertices is called a megaenvironment (Yan et al., 2000; Yan \& Tinker 2006; Yan, 2011). Figures 1-3 display GGE biplots for the three trials with an objective to identify specifically adapted genotypes, i.e., 'which genotypes performed significantly better in which location'. The singular value decomposition of GGE interaction in two dimensions explained $87 \%$ of variation for SBWYT in 2014-15 and over $95 \%$ in all other trials and years. The Baghlan discriminated the genotypes maximally in each trial. We observed formation of mega-environment comprising more than one locations as: Baghlan and Nangarhar (SBWYT, 2014-15, Figure 1), Mazar and Baghlan (ISBWYT, 2015-16, Figure 2) and all the locations in SBWYT (2015-16, Figure 1) and ESBWYT (2014-15, Figure 3). While the other cases support that the three locations represent diverse environments for genotypes evaluations, the above information can be used for understanding specific locations and exploring new environments.

The winners or specifically adapted genotypes for a chosen location or a mega-environment are located at the vertices of the polygon near the location. Winners for some mega-environments are SG10 at Baghlan and Nangarhar in 2015 and SG4 at all the locations in 2016 for SBWYT (Figure 1); IG8 at Baghlan and Mazar in ISBWYT (2015-16) (Figure 2). The winners for single location environments included SG4 at Mazar (2015, SBWYT), IG4 at Nangarhar (2016, ISBWYT), EG6 (Solh 2002 used as check) at all the locations (2015, ESBWYT), and EG9 at Nangarhar (2016, ESBWYT) (Figure3).

Mean values adjusted for incomplete block effects are given in Table 4. Some high yielding genotypes are reported here for individual locations to crosscheck if they are supported by the GGE biplots. In the SBWYT, the highest yielding genotypes at Baghlan, Mazar and Nangarhar, were SG10 with mean yield of $5.54 \mathrm{t} / \mathrm{ha}, \mathrm{SG} 4(5.18 \mathrm{t} / \mathrm{ha})$ and SG12 (4.63 t/ha) in 2015. The GGE biplot supported specific adaptation of SG4 at Mazar and SG10 for the mega-environment formed by Baghlan and Nangarhar. During 2016, the top yielding genotypes were SG4, SG11 and SG14 at those three locations respectively while GGE biplot supported SG4 for a single mega-environment comprising of all the locations. 

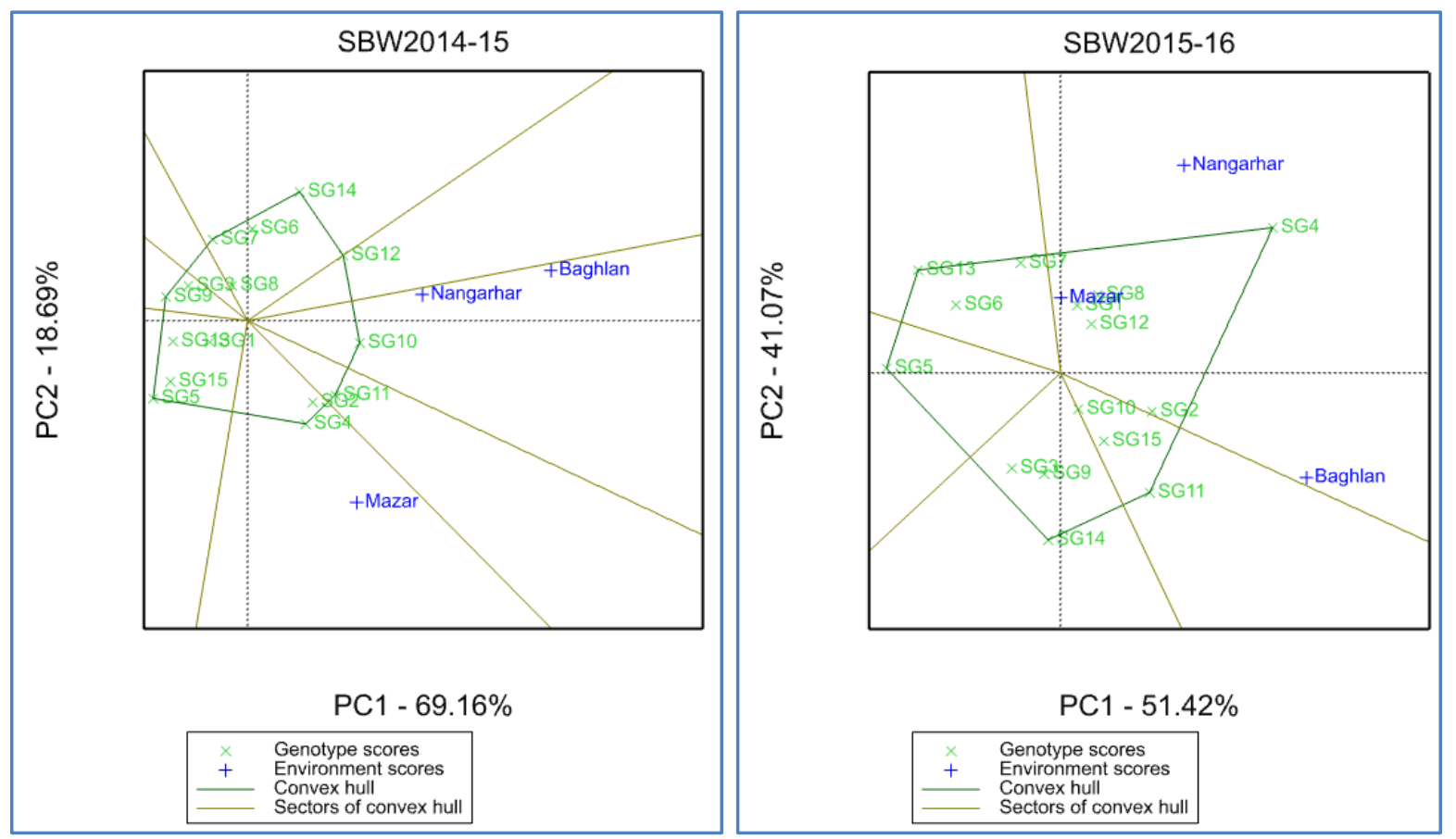

Figure 1 Genotype main effect plus genotype $\times$ environment interaction (GGE) biplot (scatter plot) for genotypes (SG1...SG15) (Table 1) and environments (Baghlan, Mazar and Nangarhar) for grain yield under trial 14th-SBWYT 2014-15 and 2015-16. Plots are environment focused and without normalization of GGE data.
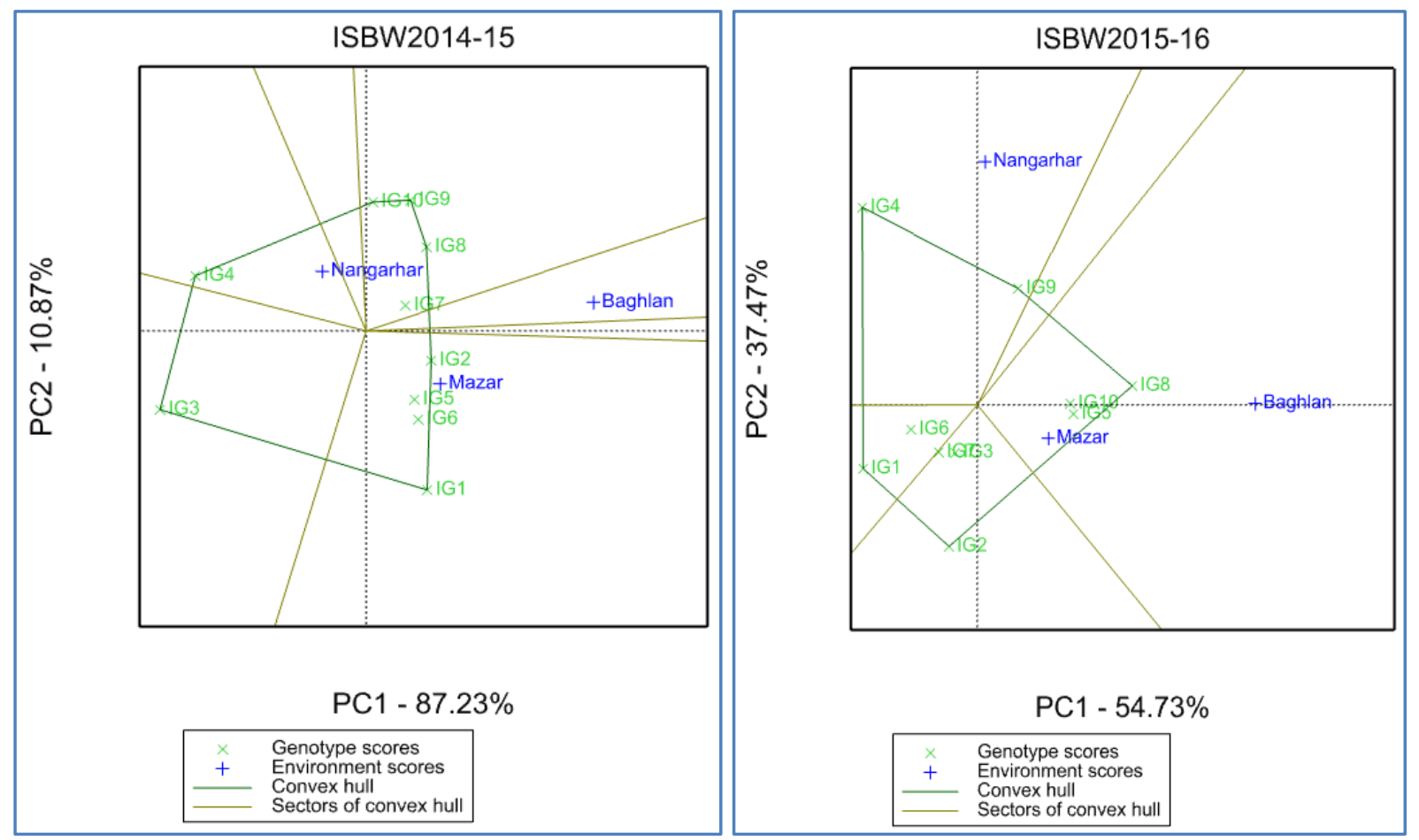

Figure 2 Genotype main effect plus genotype $\times$ environment interaction (GGE) biplot (scatter plot) for genotypes (IG1 ...IG10) (Table 1) and environments (Baghlan, Mazar and Nangarhar) for grain yield under trial 14th-ISBWYT 2014-15 and 2015-16. Plots are environment focused and without normalization of GGE data.

Journal of Experimental Biology and Agricultural Sciences

http://www.jebas.org 

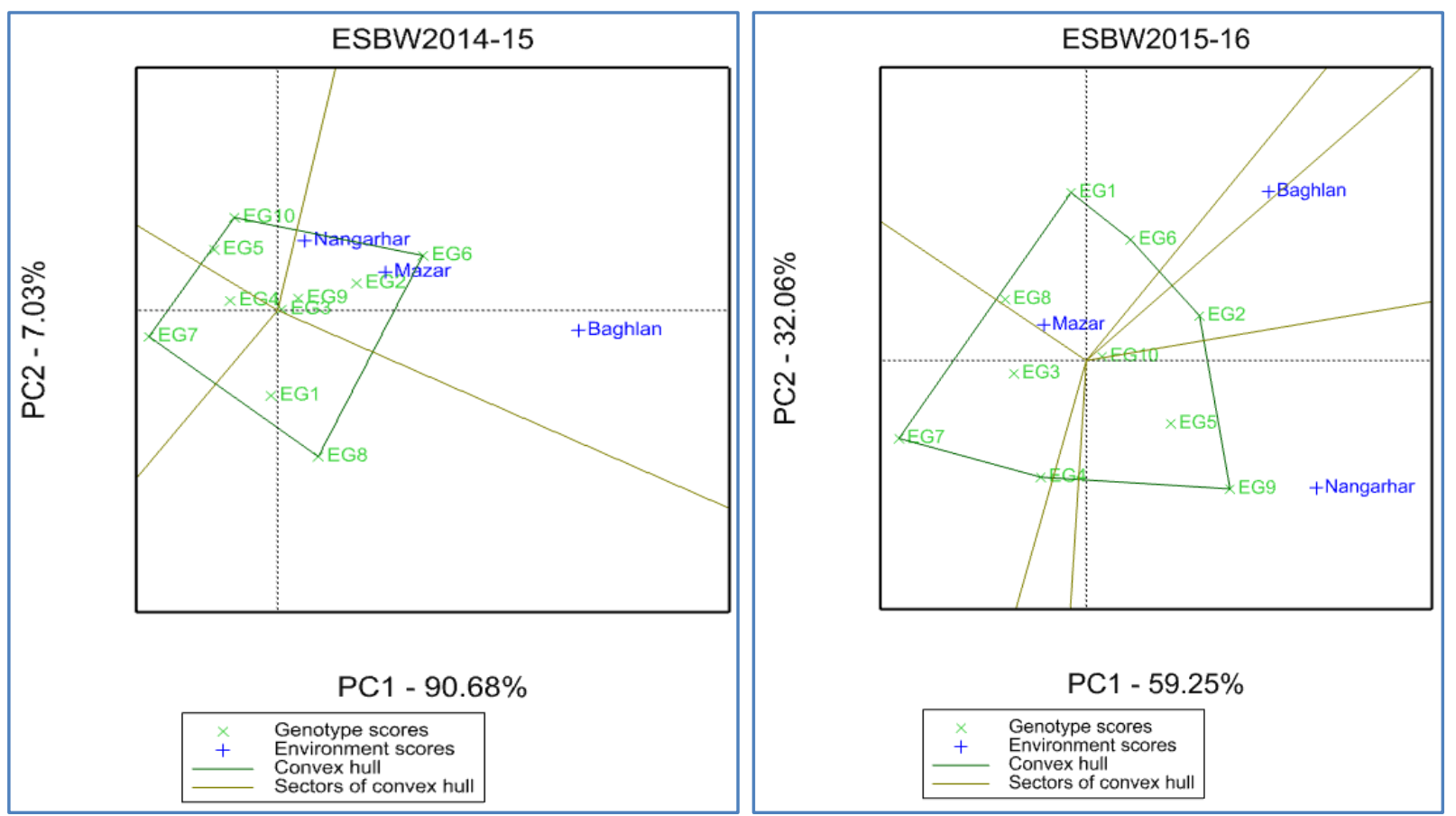

Figure 3 Genotype main effect plus genotype $\times$ environment interaction (GGE) biplot (scatter plot) for genotypes (EG1 ...EG10) (Table 1) and environments (Baghlan, Mazar and Nangarhar) for grain yield under trial 14th-ESBWYT 2014-15 and 2015-16. Plots are environment focused and without normalization of GGE data.

For the ISBWYT, the top yielders were IG8 at Baghlan (with yields $9.14 \mathrm{t} / \mathrm{ha}$ in 2015 and $3.90 \mathrm{t} / \mathrm{ha}$ in 2016), and Mazar (2.88 t/ha in 2016) and IG4 at Nangarhar (5.44 t/ha in 2015 and $5.69 \mathrm{t} / \mathrm{ha}$ in 2016). In the ESBWYT, EG6 (Solh 2002) was highest yielding at each location in 2014-15 and EG6, EG2 and EG9 were the top lines in 2015-16. These were in general supported by the biplots (Figures 1-3).

There are very limited published studies on GEI in wheat in context of Afghanistan environments. However, there are several studies that can be appraised for the similar approaches as followed in this study. Based on a set of seven environments over three years in south Tigray Ethiopia, Mehari et al., (2015) observed the presence of significant GEI in bread wheat and detected three mega-environments using GGE biplots. Our study dealt with similar situation with a difference that our study is limited to only three locations and very often each of them represents a megaenvironment. Also our study involved incomplete block designs while Mehari et al. (2015) had all their trials in RCBDs. In GGE biplot analysis, one identifies the genotypes not only for the its favorable GEI but also convincingly for its general performance across all the environments. However, a number of studies have focused on the favorable GEI for specific adaptation and low interaction for broad adaptation using additive main effects and multiplicative interaction (AMMI) analysis (Gauch \& Zobel, 1988). For example eight wheat lines developed in Central Sudan and four commercial checks were evaluated, using AMMI analysis, by Mohammed (2009) for their stability under arid conditions of Northern Sudan across five testing environments during 1992-96. Muhe \& Assefa (2011) evaluated 18 bread wheat genotypes and a standard check at three locations in Ethiopia and applied AMMI analysis for identifying stable and high yielding genotypes for the rainfall wheat production system in Ethiopia. Since the present study based on ISWBYT materials are also intended for the irrigated systems in Afghanistan, therefore sharing of the materials with those of Muhe \& Assefa (2011) could lead to promising genotypes for Afghanistan. Mohamed (2013) analyzed ten wheat genotypes in 12 environments in Egypt using both the approaches: GGE biplot and AMMI analysis. The AMMI analysis indicated a relatively more complex pattern in GEI resulting from the first three significant interaction principal components but the genotypes were inferred using GGE biplots. In Afghanistan neighboring countries, specific adaptation of wheat genotypes have been reported by Kaya et al. (2006) for Turkey and Farshadfar et al. (2012) for Iranian environments where GEI were exploited using GGE biplots on the lines of the present study, while stability analysis using AMMI and response to environment based on linear regression functions were used by Sial et al. (2000) under environments in Pakistan. Since we found significant genotype by year interaction within location, this limits the scope of specific adaptation of a genotype to a single location. In future, we intend to continue explore GEI with more selected genotypes from the present study and other sources but including more locations to represent a much wider target environment including more years. 
Table 4 Genotypes means for grain yield at the three locations in Afghanistan, $2014-2016$.

\begin{tabular}{|c|c|c|c|c|c|c|c|c|}
\hline \multicolumn{2}{|c|}{ Trial name } & \multicolumn{3}{|c|}{ 2014-15 } & \multicolumn{3}{|c|}{ 2015-16 } & \multirow{2}{*}{$\begin{array}{c}\text { 2014-16 } \\
\text { Mean }\end{array}$} \\
\hline SBWYT & Genotype code ${ }^{\$}$ & Baghlan & Mazar & Nangarhar & Baghlan & Mazar & Nangarhar & \\
\hline & SG1 & 4.46 & 4.66 & 4.12 & 4.20 & 3.00 & 4.28 & 4.12 \\
\hline & SG2 & 5.25 & 5.12 & 4.08 & 4.81 & 2.70 & 4.04 & 4.33 \\
\hline & SG3 & 4.82 & 4.41 & 3.30 & 4.21 & 2.62 & 3.41 & 3.80 \\
\hline & SG4 & 5.13 & 5.18 & 4.14 & 5.00 & 2.80 & 5.24 & 4.58 \\
\hline & SG5 & 4.19 & 4.75 & 3.64 & 3.30 & 2.59 & 3.59 & 3.67 \\
\hline & SG6 & 4.89 & 4.33 & 4.24 & 3.52 & 2.65 & 4.07 & 3.95 \\
\hline & SG7 & 4.81 & 4.29 & 3.78 & 3.79 & 2.96 & 4.35 & 4.00 \\
\hline & SG8 & 4.83 & 4.50 & 3.93 & 4.18 & 2.30 & 4.59 & 4.05 \\
\hline & SG9 & 4.26 & 4.39 & 3.93 & 4.37 & 2.47 & 3.52 & 3.82 \\
\hline & SG10 & 5.54 & 5.00 & 4.39 & 4.39 & 2.50 & 3.92 & 4.29 \\
\hline & SG11 & 5.34 & 5.14 & 4.26 & 4.99 & 2.63 & 3.65 & 4.34 \\
\hline & SG12 & 5.39 & 4.63 & 4.63 & 4.28 & 2.72 & 4.31 & 4.33 \\
\hline & SG13 & 4.33 & 4.58 & 3.81 & 3.24 & 2.72 & 4.12 & 3.80 \\
\hline & SG14 & 5.30 & 4.30 & 4.30 & 4.51 & 2.14 & 3.29 & 3.97 \\
\hline & SG15 & 4.19 & 4.72 & 3.93 & 4.55 & 2.10 & 3.94 & 3.90 \\
\hline & $\mathbf{S E}$ & 0.25 & 0.24 & 0.17 & 0.23 & 0.19 & 0.27 & \\
\hline & LSD5\% & 0.72 & 0.59 & 0.49 & 0.54 & 0.46 & 0.77 & \\
\hline \multicolumn{9}{|l|}{ ISBWYT } \\
\hline & IG1 & 8.88 & 5.10 & 4.35 & 1.61 & 2.77 & 4.03 & 4.45 \\
\hline & IG2 & 9.05 & 4.93 & 4.76 & 2.46 & 2.40 & 3.45 & 4.51 \\
\hline & IG3 & 6.52 & 4.12 & 5.01 & 2.49 & 2.43 & 4.09 & 4.11 \\
\hline & IG4 & 6.98 & 4.10 & 5.44 & 1.77 & 1.90 & 5.69 & 4.31 \\
\hline & IG5 & 8.83 & 5.11 & 4.83 & 3.43 & 2.77 & 4.39 & 4.89 \\
\hline & IG6 & 8.89 & 4.87 & 4.49 & 2.01 & 2.77 & 4.30 & 4.55 \\
\hline & IG7 & 8.89 & 4.67 & 4.88 & 2.47 & 1.95 & 4.03 & 4.48 \\
\hline & IG8 & 9.14 & 4.72 & 5.10 & 3.90 & 2.88 & 4.60 & 5.06 \\
\hline & IG9 & 9.07 & 4.44 & 5.11 & 2.95 & 2.66 & 5.24 & 4.91 \\
\hline & IG10 & 8.73 & 4.22 & 5.08 & 3.40 & 2.74 & 4.46 & 4.77 \\
\hline & SE & 0.52 & 0.29 & 0.21 & 0.17 & 0.23 & 0.45 & \\
\hline & LSD5\% & 1.43 & 0.84 & 0.60 & 0.42 & 0.64 & 1.23 & \\
\hline \multicolumn{9}{|l|}{ ESBWYT } \\
\hline & EG1 & 6.85 & 4.89 & 3.44 & 4.49 & 2.22 & 3.28 & 4.19 \\
\hline & EG2 & 7.96 & 5.43 & 4.06 & 4.51 & 2.56 & 4.44 & 4.82 \\
\hline & EG3 & 6.91 & 5.11 & 3.80 & 3.52 & 2.54 & 3.61 & 4.25 \\
\hline & EG4 & 6.29 & 4.50 & 4.00 & 3.24 & 2.05 & 3.97 & 4.01 \\
\hline & EG5 & 5.95 & 4.71 & 4.06 & 3.99 & 1.90 & 4.48 & 4.18 \\
\hline & EG6 & 8.83 & 5.90 & 4.20 & 4.55 & 2.14 & 3.73 & 4.89 \\
\hline & EG7 & 5.07 & 4.43 & 3.50 & 2.80 & 2.34 & 3.15 & 3.55 \\
\hline & EG8 & 7.67 & 4.70 & 3.45 & 3.80 & 2.17 & 3.25 & 4.17 \\
\hline & EG9 & 7.23 & 4.87 & 4.08 & 3.97 & 1.85 & 4.99 & 4.50 \\
\hline & EG10 & 6.19 & 4.90 & 4.19 & 3.98 & 1.70 & 3.85 & 4.14 \\
\hline & SE & 0.37 & 0.30 & 0.10 & 0.23 & 0.19 & 0.21 & \\
\hline & LSD5\% & 0.91 & 0.52 & 0.29 & 0.48 & 0.47 & 0.59 & \\
\hline
\end{tabular}

SE: Standard error. $L S D 5 \%=$ Least significant difference at 5\% level of significance; SBWYT= Spring bread wheat yield trials. ISBWYT= Irrigated spring bread wheat yield trials. ESBWYT= Elite spring bread wheat yield trials; ${ }^{\$}$ Names of genotypes associated with these codes are in Table 1. 


\begin{abstract}
233
Conclusions

This study summarizes three multi-location and two-year trials for evaluation of spring bread wheat genotypes on their grain yield response to the diverse environments in Afghanistan. In general, genotypic differences and genotype $\times$ location interaction and genotype $\times$ year interactions within locations were found statistically significant. This fact points to be cautious of single year results. More than two testing-years will be needed to draw final conclusion on specific adaptation. The genetic materials were an improved set of genotypes and these trials led to identify several overall high yielding genotypes, some of them may also be specifically adapted to the locations. The high yielding genotypes identified were: 1) SG4 (HAMAMA-4)and SG10 (SER.1B*2/3/KAUZ*2/BOW//KAUZ/4/KAUZ/FLORKWA-1) from the SBWYT, respectively, for overall the environments, and specifically to Baghlan and Nangarhar (2015); and 2) IG8 (VEE\#7//MT773/EMUS/3/SAFI-1) from ISBWYT overall and specific to Baghlan, IG4 (BT1735/ACHTAR//FSFOOR-1) for Nangarhar, and 3) EG6 (Solh 2002) from ESBWYT for overall the environments. These genotypes can be used for further demonstration trials in farmer's fields and adopted for large scale production to support food security in Afghanistan.
\end{abstract}

\section{Acknowledgements}

Authors thank the reviewers for their constructive comments and suggestions which substantially improved the presentation of an earlier version of the manuscript. Authors gratefully acknowledge the International Fund for Agricultural Development (IFAD) for financial support, and the Department of Agriculture, Irrigation and Livestock (DAIL) and Ministry of Agriculture, Irrigation and Livestock (MAIL), Afghanistan for providing research platform facilities, and thank the field technicians Mssrs. Nooralhaq Hakimi, 'Abdul Rahman Rahmani, Naween Safi, Mawya Masomi, Adulhaq Farhang and Hedayet Safi for collecting the data from the trials presented.

\section{Conflict of interest}

Authors would hereby like to declare that there is no conflict of interests that could possibly arise from this study.

\section{References}

Asfaw A, Alemayehu F, Gurum F, Atnaf M (2009) AMMI and SREG GGE biplot analysis for matching varieties onto soybean production environments in Ethiopia. Science Research Essays 4 : 1322-1330.

Basford KE, Cooper M (1998) Genotype x environment interaction and some considerations of their implications for wheat breeding in Australia. Australian Journal of Agricultural Research 49:153-174

CSO (Central Statistics Organization - 2014)
Afghanistan.http://www.cso.gov.af/en, accessed on 15/03/2017.

DeLacy IH, Basford KE, Cooper M, Fox PN (1996a) Retrospective analysis of historical data sets from multienvironment trials- Theoretical development. In: Cooper M; Hammer GL (Eds) :'Plant Adaptation and Crop Improvement', CAB International: Wallingford, UK Pp. 243-267.

DeLacy IH, Ratnasiri WGA, Mirzawan PDN (1996b) Retrospective analysis of historical data sets from multienvironment trials-Case studies. In: Cooper M, Hammer GL (Eds): 'Plant Adaptation and Crop Improvement', CAB International: Wallingford, UK Pp. 269-290.

Eberhart SA, Russell WA (1966) Stability parameters for comparing varieties. Crop Science 6: 36-40.

FAO (2014) FAOSTAT. Food and Agriculture Organization of the United Nations, Rome, Italy.

Farshadfar E, Mohammadi R, Aghaee M, Vaisi Z (2012) GGE biplot analysis of genotype $x$ environment interaction in wheat-barley disomic addition lines. Australian Journal of Crop Science 6 :1074-1079.

Finlay KW, Wilkinson GN (1963) The analysis of adaptability in plant breeding programme. Australian Journal of Agricultural Research14: 742-754.

FEWS Net (2015) Regional Wheat Supply and Market Outlook. FEWS Net. Kabul https://mail.gov.af/en/page/foodsecurity-early-warning-projects-fews-net, accessed on $15 / 03 / 2017$

Gauch HG, Zobel RW (1988). Predictive and postdictive success statistical analyses of yield trials. Theoretical and Applied Genetics 76:1-10.

Jambormias E, Riry J (2008) Application of GGE biplot for stability and adaptation evaluation of genotypes with multi environment trials data (in Indonesian). Journal Agriculture 4 : 84-93.

Jambormias E (2011) Describing of GGE-biplot graphics to evaluate genotypes performance and changes of environmental stress in small islands (in Indonesian). Proceedings of National Conference: Development of Small Islands (PERMAMA). University of Pattimura. Ambon. p. 299-310.

Kaya Y, Akcura M, Taner S (2006) GGE-biplot analysis of multi- environment yield trials in bread wheat. Turkish Journal of Agriculture and Forestry 30:325-337. 
Lin CS, Binns MR (1988) A method of analyzing cultivar x location $\mathrm{x}$ year experiments: a new stability parameter. Theoretical and Applied Genetics 76:425-430.

Manan AR, Wassimi N (2003) Wheat Production Guide For Afghanistan. ICARDA, Kabul.

Mehari M, Tesfay M, Yirga H, Mesele A, Abebe T, Workineh A, Amare B (2015) GGE biplot analysis of genotype-byenvironment interaction and grain yield stability of bread wheat genotypes in South Tigray, Ethiopia. Communications in Biometry and Crop Science 10: 17-26.

Muhe K, Assefa A (2011) Genotypes X environment interaction in bread wheat (Triticum aestivum L.) cultivar development in Ethiopia. International Research Journal of Plant Science 2: 317-322.

Mohammed MI (2009) Genotype X environment interaction in bread wheat in Northern Sudan using AMMI analysis. American-Eurasian Journal of Agricultural \& Environmental Sciences 6: 427-433.

Mohamed NEM (2013) Genotype by environment interactions for grain yield in bread wheat (Triticum aestivum L.). World Journal of Agricultural Research and Food Safety 1:27-33.

RASTA(2012)Wheat Market and Wheat Availability in Afghanistan. RASTA, Kabul.

Sharma RC, Morgounov AI, Braun HJ, Akin B, Keser M, Bedoshvili D, Bagci A, Martius C, van Ginkel M (2010)
Identifying high yielding stable winter wheat genotypes for irrigated environments in Central and West Asia. Euphytica 171: 53-64.

Sial MA, Arain MA, Ahmad M (2000). Genotype x environment interaction on bread wheat grown over multiple sites and years in Pakistan. Pakistan Journal of Botany 32:8591.

VSN International (2015) The Guide to the Genstat Command Language (Release 18), Part 2 Statistics. VSN International, Hemel Hempstead, UK

Yan W (2011) GGE Biplot vs. AMMI graphs for Genotype-byEnvironment Data analysis. Journal of Indian Society of Agricultural Statistics 65:181-193.

Yan W, Hunt LA, Sheng Q, Szlavnics Z (2000) Cultivar evaluation and mega-environment investigation based on GGE biplot. Crop Science 40: 597-605.

Yan W, Tinker NA (2006) Biplot analysis of multienvironment trial data: Principles and applications. Canadian Journal of Plant Science 86: 623-645.

World Bank (2008) Afghanistan Regional food price. World Bank, Kabul. 